\title{
Quality Criteria for Lesson and Learning Studies as forms of Action Research
}

Quality as Experienced v Quality as Measured.

Two views of quality are often seen as standing in tension with each other (Stake and Schwandt, 2006). Quality as experienced implies the discernment of quality as a form of practically embodied knowledge, which is both cognitive and emotional and takes the form of 'experience-near understandings'. Under these conditions quality is represented through narratives of personal experience (see Author 2007 p.230). Quality as measured involves a distancing-from-experience. Discernments of quality involve explicit comparison of the object in question with a set of standards for it. Stake and Schwandt (2006 pp.404-418) point out that the meaning of quality, is structured by a set of constructs that are derived from the community of discourse to which the evaluator belongs rather than to the actions and language of the evaluand.

Assessing the quality of practice-based educational action research in an academic context: a critical issue.

Assessments of practice-based action research in educational organizations, such as schools, which are carried out in the context of postgraduate Higher Education Awards may embody a tension between quality as experienced and quality as measured. In my own university, for example, we have a standards template against which assessments of all Masters-Level work across Faculties and Departments is expected to be 'measured'. Its main categories are as follows:

Classification;

Learning outcomes and scholarship;

Presentation;

Methodology;

Argument and Understanding;

Criticality and Analysis;

Use of Sources and Evidence.

Such categories tend to be underpinned by a mind-body dualism in which the intellectual virtues are abstracted from practical experience in the context of action to effect change. They are basically shaped by a cultural script that has traditionally demarcated academic communities and their constitutive theoretical languages from the language of the practical. They presuppose a boundary between the realms of theory and practice. In this context assessments of practice-based research rarely make explicit any tension assessors discern between quality as it is experienced by the facilitators (often the academics doing the assessment) and practitioners participating in the research. This is reinforced by the requirement to specify levels of achievement in relation to the categories specified in the template. Hence, in my own university academic assessors are required to sum up the quality of the work of post-graduate students depicted in the template as follows: 
Distinction: 100-70 \%( Upper, Middle, Lower Range); High Merit (69-65\%) and Merit (6460\%); Pass (59-55\%) and Pass (54-50\%).

What follows is an attempt on my part to distil, from my own experience of facilitating and participating in lesson and learning study as forms of practice-based educational action research, some explicit quality criteria that can be used to inform my assessments of such research in the context of Masters-Level work carried out by teachers in their work place. In doing so my aim is to provide a basis for interpreting general standards templates, and judgements about levels of achievement, in ways that make them more consistent with the language of practical reasoning, and therefore less distanced from the experience of teachers as researchers in the context of their attempts to bring about significant change in their classrooms. I hope that this will help other academic facilitators of lesson and learning study to reflect about their own experience of high quality work in this field, and in doing so to test and revise the criteria set out below.

\section{What makes lesson study a form of high quality educational action research?}

In this section I will draw on quality criteria that I distilled from reflecting on my own experience as a participant in, and facilitator of, action research (see Author 2007). I would claim that Lesson study will constitute a form of high quality practice-based action research if:

- It focuses on a problem that is experienced by the teachers involved as of real practical concern to them. Such a problem maybe experienced at an emotional level without being understood.

- It seeks to understand a practical problem that teachers experience in their teaching by gathering data about it from a variety of perspectives, such as that of the teacher directly experiencing the problem, classroom observers, and the students. This process of gathering data about a problem experienced in practice from different perspectives is often referred to as 'triangulation'.

- It enables teachers to call their existing stock of professional knowledge - in the form of the 'tacit theories' or 'cultural scripts' that underpin and shape their practice - into question, and to test it against evidence gathered in their practical situation. Triangulation data should be used to extend and broaden a teachers' understanding of their practical situation in a way that opens up new possibilities for action in it.

- It constitutes a rigorous conversational and democratic process of practical reasoning (phronesis) in which teachers open up their practice to the rational scrutiny of students and peers, whose views of the action situation they 'invoice', and in doing so demonstrate a disposition to subordinate their own prejudices to the search for an overlapping and un-coerced consensus. Within this deliberative and self-reflexive process of practical reasoning means and ends become objects of mutual reflection. Teachers not only call into question their teaching strategies (means) but also their aims (ends) to which their strategies are directed. They modify each by reflecting on the other. This process is characterised by certain virtues enacted by its participants; namely, integrity in the pursuit of educational aims and values, curiosity about other people's understanding of the situation, objectivity and honesty about one's own motives and reasons for action, open-mindedness towards the views of others and respect for their freedom of thought and action.

Good action research in classrooms is a democratic process of knowledge construction, characterised by: 
a) The ability of teachers to discern common features across a range and variety of classroom situations that are practically significant for educational action, and to collaboratively construct knowledge about how to realize their aims and values in particular concrete situations;

b) Teachers reflecting about and developing shared understandings of their educational aims and values by deliberating together on the actions they take to give them practical expression in their teaching;

c)the collaborative development of a body of shared understandings and insights in a publicly accessible form for other teachers to test in their classrooms; d) the development of an experimental approach to teaching in a sustainable form across a professional learning network of teachers.

Theory-informed Lesson Study: can it be cast in the form of high quality action research?

Some might argue that the experience of facilitating and conducting theory-informed lesson study provide quality criteria for practice-based research projects that are more clearly matched to traditional standards of academic scholarship? This is because they assume that theory-informed learning study implies a greater distancing from professional practice than the action-research approach to teachers' professional development?

However, one particular theoretical perspective on learning that has been used to inform lesson study appears to possess a distinctive relationship to educational practice; namely, the theory of variation (see Marton and Booth, 1997). This is because it is grounded in the phenomenographic study of students' actual learning experiences in lessons. Good teaching informed by variation theory will:

i) Focus on depicting students' ways of experiencing the object of learning and in "revealing and describing the variation therein". As such it will reveal an educational interest "in the variation and change in capabilities for experiencing---particular phenomena in the world in certain ways" (Marton and Booth 1997 p.111);

ii) Be explicitly aimed at deepening understanding of the object of learning. Pedagogical design in the light of this aim will place capabilities for experiencing phenomena in certain ways as objects of understanding in a pedagogically significant hierarchical order. From the point of view adopted some capabilities "can be seen as more advanced, more complex, or more powerful than other capabilities" (Marton and Booth p.111).

iii) Demonstrate that differences between students capabilities for experiencing the object of learning are educationally critical, and that changes between them constitute the most important aspects of learning (see Marton and Booth 1997 p.111), and effecting such changes the most important pedagogical task for teachers.

Lesson study, conceived as a form of educational action research informed by the theory of variation, emerged in contexts where the lesson study method was being globalised beyond its 'home' in Japan. The curriculum reforms in post-colonial Hong Kong provided a context for Lo Mun Ling to bring together and fuse Japanese Lesson Study as a collaborative form of practice-based research, with Stenhouse and Author's idea of 'teachers as action researchers', and with Marton's variation theory. This synthesis of ideas, circulating in Hong Kong in the early $21^{\text {st }}$ century, was termed learning study by Lo and her co-workers. While a PhD student undertaking a case study of curriculum development in a Hong Kong school Lo engaged with 
the work of Author and Marton, who were both advisory professors working on the HK curriculum reforms at the time. Author's work to facilitate the development of 'teachers as researchers' as a means of bringing about curriculum change emphasised the significance of Stenhouse's 'process model' of curriculum design (see Author pp.135-139, and Stenhouse 1975 pp. 84-97) as a focus for action research in contrast to the dominant 'objectives model'. Stenhouse advocated the use of principles of procedure to define a worthwhile educational process implied by an educational aim. Marton's work yielded a pedagogical theory that also focused the attention of 'teachers as researchers' on the quality of the learning process in itself as opposed to 'measureable learning outcomes'. Learning study has now taken root beyond Hong Kong, particularly in Sweden, Brunei, Austria, and parts of the UK.

In the light of the above account of conceptual change good learning studies will be experienced as teachers attempts in their classrooms to realize pedagogical principles of procedure that are implied by variation theory, and which specify necessary conditions of learning. Such principles maybe cast in the following terms:

1) Direct students' attention to critical aspects and features of the object of learning;

2) Enable students to discern critical features of the object of learning by getting them to experience contrasting views of the object along a-similar dimension of variation (aspects);

3) Enable students to discern the critical features and aspects of an object of learning simultaneously;

4) Enable students to deepen their understanding of a phenomenon by progressively differentiating its critical features (values) from the whole, and thereby opening up the major dimensions of variation that constitute it as an object of learning;

5) Enable students, as their understanding of an object of learning unfolds, to make generalizations by attending to what remains invariant in the background of variable appearances e.g. to define what makes a geometric figure a triangle in terms of three sides and 180 degrees as the sum all angles (see Lo \& Marton 2012 p.11).

6) Adopt an experimental approach to developing teaching strategies for handling curriculum content in the light of variation theory, and thereby improving both practice and the theory itself. e.g. testing the finding that from the standpoint of variation theory contrast should precede generalization, by experimenting with a different interpretation of the theory; namely, presenting contrast after generalization (see Ko Po Yuk 2014 pp.285-287).

In the light of the above account of variation theories underpinning pedagogical aims and principles what then counts as a good learning study report?

A good learning study report will:

- Depict a dynamic relationship between the Intended, enacted, and lived object of learning, that is well-grounded in:

a) data from staff and expert planning meetings:

b) observational data used in post-lesson reviews of research lessons about patterns of classroom interaction between students, and between teacher and students in relation to the content of the research lessons; 
c) questionnaire and interview data about the students' lived experience of the lesson content and about their lived experience as learners in classrooms generally.

- Extend the theory of variation used to assess the impact of the study to cover the professional learning of teachers as well as student learning about the object of learning.

Lo and Pong (2005) discriminated three dimensions of variation in assessing the impact of their first LS project on the teachers involved; namely,

V1.Variation in students' experience and understanding of content;

V2. Variation in teachers' approaches to handling the object of learning as evidenced in planning meetings and discussions e.g. in their discernment of its critical features; V3. Variation as a guiding principle of pedagogical design, i.e. the use teachers make of patterns of variation in enabling teachers to discern critical features of the object of learning.

- Use extended variation theory to reflect on and explore changes along all the above dimensions of variation in a way that depicts the learning of students and teachers as a process that constitutes the 'object of learning', and thereby challenges certain assumptions about the use of variation theory as a pedagogical design framework; namely, first to describe the object of learning in its own right and then describe what the learner learns about it (see Marton and Booth 1997 p.161)."

- Treat the educational aim of 'developing an understanding of the object of learning' as inexhaustible with no fixed end-point.

- Identify educationally significant differences in the way both students and their teachers experience the object of learning (V1 \& V2).

- Identify problems in realizing the principles of discussion in the classroom and teachers' planning and review meetings.

- Assess the impact of discussion in classrooms and in planning and reviewing 'research lessons' on changing conceptions of the object of learning amongst participating students and teachers.

- Identify the links between students and teachers different ways of seeing the object of learning, and persistent controversial value issues that surround the discernment of critical aspects and features of the object amongst experts.

- Demonstrate what makes the selection and pedagogical handling of an object of learning educationally worthwhile by providing evidence of its impact on the learner's capability to make sense of their 'life world'. This is an important dimension of 'deep' as opposed to surface understanding.

- Systematically generate and articulate 'findings', in the form of general hypotheses about a) the critical features of an object of learning, and b) the effective use of patterns of variation (V3),which can be tested by teachers in their classrooms (see Kullberg 2012 pp. 232-244, and Runesson \& Gustafsson 2012 pp.245-260, and Author 2012 pp. 108-125).

Are the quality criteria for lesson study as a form of practice-based action research and Learning Study well-matched?

- The characterization of good learning studies outlined in the criteria above appear to be very well matched to the quality criteria stated for good action research and vice versa. 
They may be regarded as mutually illuminating. For example, the three dimensions of variation marked out in the extended theory of variation is very congruent with the principle of using triangulation data to extend and broaden a teachers' understanding of their practical situation in a way that opens up new possibilities for action in it. Also, both sets of criteria match significant features of the 'process model' of curriculum development in contrast to the 'objectives model' (see Stenhouse 1975 p. 84-97).

Some have argued that practice-based action research is an atheoretical process. This appears to invalidate the claim that Learning Study, informed by variation theory, constitutes a form of action research, at least of the kind depicted by Stenhouse. Yet Stenhouse (1975 p. 157) argued that teachers needed a "common vocabulary of concepts and a syntax of theory" in order to communicate with each other in a context of collaborative action research. He did, however, argue that such a theory needed to have practical significance for teachers, who were less interested in generalizing beyond their experience of their own particular classrooms. The theory of variation, given its phenomenographic grounding, serves such a function.

Phenomenographical inquiry and theory construction (see Marton and Booth, 1997 pp. 110136).

Variation theory expresses an interest in understanding phenomena as others experience them in and across particular contexts of action and "in revealing and describing the variation therein" and not as the researcher experiences them from a more distanced academic/abstract standpoint. This represents an educational interest in which other people's different ways of experiencing phenomena are viewed as 'educationally critical differences'.

Variation theory can therefore be contrasted with more abstract learning theories, such as 'constructivism, that embody a dualistic picture of the mind on the presumption that:

“--- all psychological explanation must be framed in terms of internal mental representation, and processes (or rules) by which these representations are manipulated and transformed" (Marton and Booth p.163).

Variation theory implies less mind-body dualism than some other learning theories, and therefore less distancing from teachers' experience of the practical context of their work.

\section{References.}

Author, J (2007) Assessing the quality of action research, Research Papers in Education, 22(2).

Author, J (1974) Sex role constraints on freedom of discussion, The New Era, 55 (6).

Author, J (1976/77) Developing hypotheses about classrooms from teachers' practical constructs, Interchange, 7(2).

Author, J (2012) Developing a science of teaching through lesson study, International Journal of Lesson and Learning Studies, 1(2).

Ko Po Yuk (2014) Learning study - the dual process of developing theory and practice, International Journal of Lesson and Learning Studies, 3(3). 
Kullberg, A (2012) Can findings from learning studies be shared by others? International Journal of Lesson and Learning Studies, 1(3).

Lo, M.L. \& Pong, W.Y. (2005), Catering for individual differences: building on variation, Lo, M.L., Pong,W.Y \& Chik, P.M. (Eds). Catering for Individual Differences through Learning Studies (Hong Kong: Hong Kong University Press).

Lo, M.L. \& Marton, F (2012) Towards a science of the art of teaching: using variation theory as a guiding principle of pedagogical design, International Journal of Lesson and Learning Studies, 1(1).

Marton, F. \& Booth, S. (1997) Learning and Awareness (Mahwah, New Jersey: Lawrence Erlbaum Associates, Publishers).

Runesson, U \& Gustafsson, G (2012) Sharing and developing knowledge products from learning study, International Journal for Lesson and Learning Studies, 1(3).

Stake,R.E. \& Schwandt, T.A. (2006) On discerning quality in evaluation, in: I.Shaw, M.Mark \& J. Greene (Eds) Handbook of Evaluation (New York: Sage Publications).

Stenhouse, L (1970) The humanities project: the rationale, Theory into Practice, 10.

Stenhouse, L (1975) An Introduction to Curriculum Research and Development (London: Heinemann Educational). 